\title{
An Aristotelian Approach to Cognitive Enhancement
}

\author{
Lubomira Radoilska
}

Published online: 23 June 2010

(C) The Author(s) 2010. This article is published with open access at Springerlink.com

There is an underlying tension between the notion of cognitive enhancement and the idea that knowledge presupposes creditable agency. By drawing on an Aristotelian theory of action, it becomes clear that cognition is routinely considered as a human activity susceptible to kinds of appraisal, to which mere physiological processes, such as digestion, are not. In essence, we appreciate knowledge as a distinctive achievement. It includes good epistemic outcomes that are also epistemically creditable, as opposed to others that, although attributable to an epistemic agent, are, nevertheless, epistemically null.

In contrast, the term "cognitive enhancement" is related primarily to physiological and, more specifically, neuronal processes. It covers various medical techniques, including pharmacological interventions, brain stimulation and genetic manipulation that can modify neuronal functions and, possibly, convey certain epistemic benefits. ${ }^{1}$ Examples are prolonged attention span and memory retention. As a result, the issue of cognitive enhancement is typically addressed within its dedicated field of neuroethics. ${ }^{2}$ Considerations of distributive justice, such as fair access to enhancing procedures often come to the forefront of the discussion. ${ }^{3}$

\footnotetext{
1 British Medical Association, Boosting Your Brainpower: Ethical Aspects of Cognitive Enhancements (London: British Medical Association, 2007), pp. 9-15.

2 See Steven J. Marcus, ed., Neuroethics: Mapping the Field (New York: Dana Press, 2002); Judy Illes, ed., Neuroethics: Defining the Issues in Theory, Practice and Policy (New York: Oxford University Press, 2005); see also Walter Glannon, "Neuroethics," Bioethics, Vol. 20 (2006).

3 Nick Bostrom, "Human Genetic Enhancements: A Transhumanist Perspective," The Journal of Value Inquiry, Vol. 37 (2003), p. 494; also see John Harris, Enhancing Evolution: the Ethical Case for Making Better People (Princeton, N.J.: Princeton University Press, 2007).
}

L. Radoilska (凹)

Faculty of Philosophy, University of Cambridge, Sidgwick Avenue, Cambridge CB3 9DA, UK e-mail:1r271@cam.ac.uk 
Further concerns pertain to prospective effects on personal identity and individual freedoms. ${ }^{4}$ Although such concerns will not be directly addressed in the following discussion, their relevance to the existing debate will be indicated in conclusion.

The following analysis builds upon an Aristotelian theory of action as applied to epistemic pursuits. ${ }^{5}$ In this respect, it shares some background assumptions with virtue epistemology, such as a general understanding of knowledge as an apt, creditable performance. ${ }^{6}$ This, however, does not confine the conclusions to this particular theory of knowledge. They are consistent with any theory, which distinguishes between the successful exercise of someone's intellectual abilities and sheer epistemic luck.

\section{2}

The idea that intellectual achievement is constitutive of knowledge casts doubt onto the notion of good epistemic luck. The correct conclusions that a person reaches without employing a relevant skill can hardly be to her epistemic credit. On this occasion, the person is not to be congratulated as knowledgeable, although it may still be pleasing that she got things right rather than wrong. With respect to epistemic credit, purported chance seems on a par with bad luck. This initial observation will be explored in the following series of contrasting thoughtexperiments. The underlying thought is to firstly suggest that cognitive enhancement is an instance of good epistemic luck and then to identify possible ways, in which it may undermine epistemic achievement.

Linda Zagzebski presents an example in the style of cases set out by Harry Frankfurt, in which a benign manipulator ensures that a prospective knower believes only truths. ${ }^{7}$ In the scenario at issue, the manipulator monitors the belief formation of the manipulated agent and intervenes, unbeknown to her, only if she is on the verge of acquiring a false belief. The prospective knower ends up holding only true beliefs. Yet, her epistemic agency is undermined by the implicit manipulation of her reasoning. The reliability that it conveys cannot substitute for the loss of epistemic initiative, which is indispensable for gaining epistemic credit.

The preceding scenario prompts a different conclusion from that suggested by the analysis of the original Black and Jones case proposed by Frankfurt, which unfolds as follows: "Suppose someone - Black, let us say - wants Jones to perform a certain

\footnotetext{
${ }^{4}$ See Carl Elliott, Better than Well: American Medicine Meets the American Dream (New York: W.W. Norton, 2003); and Michael Sandel, The Case Against Perfection: Ethics in the Age of Genetic Engineering (Cambridge, Mass.: Harvard University Press, 2007).

${ }^{5}$ See Lubomira Radoilska, L'Actualité d'Aristote en morale (Paris: Presses Universitaires de France, 2007), pp. 191-290.

${ }^{6}$ See John Greco, "Knowledge as Credit for True Belief," in Michael R. DePaul and Linda Zagzebski, eds., Intellectual Virtue: Perspectives from Ethics and Epistemology (Oxford: Oxford University Press); see also Ernest Sosa, A Virtue Epistemology. Vol. 1: Apt Belief and Reflective Knowledge (Oxford: Oxford University Press, 2007).

${ }^{7}$ See Linda Zagzebski, "Must Knowers Be Agents?", in Abrol Fairweather and Linda Zagzebski, eds., Virtue Epistemology: Essays on Epistemic Virtue and Responsibility (Oxford: Oxford University Press, 2001), pp. 149-152.
} 
action. Black is prepared to go to considerable lengths to get his way, but he prefers to avoid showing his hand unnecessarily. So he waits up until Jones is about to make up his mind, and he does nothing unless it is clear to him (Black is an excellent judge of such things) that Jones is going to decide to do something other than what he wants him to do. If it does become clear that Jones is going to decide to do something else, Black takes effective steps to ensure that Jones decides to do and that he does do, what he wants him to do... Now suppose that Black never has to show his hand because Jones, for reasons of his own, decides to perform and does perform the very action that Black wants him to perform." 8 The resulting action is clearly attributable to Jones. Hence, concludes Frankfurt, Jones is fully responsible for it and Black's power to make him perform it all the same cannot serve as an excuse.

Although correct, this conclusion is potentially misleading if extrapolated to the earlier epistemic case. The reason for this is provided by two important asymmetries: the first between the two alternatives in the original scenario and the second between the second alternative and the epistemic setting of benign manipulation. In the case outlined by Frankfurt, Jones effectively performs the action intentionally. Being unaware of Black's ability to intervene, he does not even act under duress. Hence, Black's presence does not constitute a mitigating circumstance. Yet, if Jones is made to perform the action by Black, his responsibility as an agent will not be engaged because this action will not be of his doing in the relevant sense. Here, the particular outcome that Jones brings about is attributable to him only causally. Hence, although the consequences of both alternatives are identical, they stand in a very different relation to Jones.

Crucially, the asymmetry will not be cancelled out even if Black were to intervene in order to make sure that Jones realizes his own intention, for instance, by rectifying Jones's failure to carry out his plan. This modified scenario is relevantly similar to the example of a clumsy killer who tries to shoot someone dead, misses the victim by a mile, but his shot stampedes a herd of wild pigs that, as a result, trample his intended target to death. ${ }^{9}$ The case clearly indicates that the match between preceding intention and a wished-for result does not suffice in order to make this attributable to the agent as such rather than as a mere physical cause. Still, most of us will be inclined to hold responsible both the clumsy killer and Jones from the modified scenario. Yet, the blame that may be plausibly assigned to them pertains to what they have tried to do. Both are guilty of attempted murder, but the accidental deaths of their intended victims cannot be pinned on them. Neither is to blame for the coincidental fulfillment of his blameworthy intent.

This point is directly related to the second asymmetry mentioned above. Unlike the story of benign manipulation, the cases introduced by Frankfurt are about attributing negative responsibility, or blame. For instance, it is often stipulated that the action Black wants to see through is an assassination that Jones has agreed to

\footnotetext{
${ }^{8}$ Harry G. Frankfurt, "Alternate Possibilities and Moral Responsibility," Journal of Philosophy, Vol. 66 (1969), pp. 835-836.

9 Donald Davidson, "Freedom to Act," in Donald Davidson, ed., Actions and Events (New York: Oxford University Press, 1980), p. 78.
} 
carry out. ${ }^{10}$ However, the conditions for blame attribution are significantly less stringent than the conditions for crediting, or praising an agent. People may be plausibly held to account not only for intentional actions and their foreseeable consequences, but also for the results of avoidable omissions and negligent behavior. As suggested by the status of attempted murder as a criminal offence, negative responsibility may sometimes be engaged even though the agent was unsuccessful in carrying out her intended action. In contrast, full credit is attributable primarily to agents who successfully realize their praiseworthy intentions. This is consistent with the intuitive idea that credit should also be given to agents whose failure is due to unforeseeable circumstance. Apparent counterexamples, such as praise given for refraining from certain actions, arise from conflating the praised behavior and its outward consequences. In such cases, the agent is credited for successfully resisting a temptation that most people would have given in to. Carrying out the decision to stay away from temptation is the actual object of praise, not the by-product of having done nothing wrong.

The asymmetry between negative responsibility and praise indicates that there may be nothing epistemically benign in the case of benign manipulation. Here, Black harms Jones qua epistemic agent in two distinct ways. The first type of harm is related to robbing Jones of the epistemic credit that she could have gained if she were left to correct her mistaken beliefs by herself. By preventing the formation of Jones's potentially false beliefs, Black also limits her opportunities to gain full epistemic credit on specific occasions.

The second type of harm becomes apparent if the thought-experiment is considered from a long-term perspective. Black's regular interventions would make it increasingly difficult to give full epistemic credit to Jones even for her true beliefs that are not the direct result of manipulation. The systematic interference with her reasoning makes it impossible to isolate some beliefs as autonomously formed. Furthermore, it prevents Jones from developing critical skills which presuppose the real possibility of error. Yet, such skills are epistemically essential. Without them, Jones cannot be considered as knowledgeable, although she might be treated as a reliable source of information.

This type of harm is far-reaching and affects Jones's very status of a prospective knower, since her getting things right is fundamentally compromised from an epistemic perspective. Such deep epistemic harm is, nevertheless, compatible with certain pragmatic benefits that Jones may receive as a result of holding only true beliefs. Arguably, her planning will be improved to the extent that it does not build upon false premises. The benefits, however, do not offset the underlying damage of having her epistemic agency systematically undermined. The reason for this is that intentional agency is inseparable from the exercise of our intellectual abilities and largely depends on the success of various epistemic pursuits. In this sense, Jones's manipulated acquisition of true beliefs is not only epistemically corruptive, but may also, in the long run, compromise her overall standing as a fully creditable agent. The link between the two will become clearer at the concluding stages of the

\footnotetext{
${ }^{10}$ See David Widerker and Michael McKenna, eds., Moral Responsibility and Alternative Possibilities: Essays on the Importance of Alternative Possibilities (Aldershot, England: Ashgate, 2003).
} 
argument, where the possibility to accomplish epistemic goals by extraneous means will be related to an underlying disposition to appreciate worthy abilities and activities only for the sake of something else. This disposition alone will be shown to adversely affect the nature of someone's achievements.

\section{3}

The two types of harm identified earlier seem unavoidable even if the thoughtexperiment were modified so that Black either intervenes with Jones's prior consent, or they were one and the same person. The case of Black intervening would resemble the clumsy killer: Black's intervention would bring about a result that accords with Jones's prior intention of getting things right, whenever Jones is likely to fail realizing it. The true beliefs that Jones acquires on account of Black will not be epistemically creditable to Jones. Nevertheless, she might deserve credit for enlisting Black's assistance. The credit may be even partly epistemic if Jones is responsible for her correct opinion about Black's unfailing epistemic prowess.

Yet, a continual reliance on Black would indicate an implicit flaw of the epistemic project that Jones is pursuing. Her underlying intention to persistently come to believe only truths is at odds with a commitment to epistemic achievement to the extent that she accepts Black's interference as a possible substitute to the exercise of her own intellectual abilities. This intention is indeterminate in a significant way. It is epistemic only as a goal, not as a plan for its realization. It prepares the ground for these "two faces of intention" to fall apart. ${ }^{11}$ Jones's epistemic agency is, therefore, put at risk from having her goals realized by means, which detract from her epistemic credit and belie her seemingly strong epistemic commitment to believing only truths. Her prior consent does not cancel out these eventualities. It only turns them into more complex cases where epistemic harm and self-harm are intertwined, for Black and Jones are complicit in undermining Jones as a self-standing knower. This observation will be refined in the following discussion of partial or derivative credit for actions involving self-binding.

The situation would not change, in an epistemically relevant sense, if it is assumed that Black and Jones are one and the same person, Jones presenting her capacity qua prospective knower, Black standing for her broader intentional agency. Less artificially, Black could be replaced with a kind of device that Jones can readily employ. This could be a calculator or a performance-enhancing drug. Both cases are consistent with some epistemic self-harm: firstly, by diminishing Jones's epistemic credit for the resulting performance, and, secondly, by eventually altering her attitude toward epistemic achievement.

The first point is straightforward. When Jones gets the answer of a complex multiplication by using a calculator, she does not exhibit mathematical competence. This does not mean that Jones does not know the correct answer. Yet, the knowledge is second-hand and relevantly dissimilar from that of a mathematically skilful person who gets the answer on her own. On such occasions, Jones may

\footnotetext{
11 See Michael Bratman, "Two Faces of Intention," Philosophical Review, Vol. 93, No. 3, (1984).
} 
deserve pragmatic credit for managing to get by, but not for applying, let alone developing a relevant intellectual skill. The related loss of opportunity and resulting epistemic harm may sometimes be trivial, or well worth undergoing. Developing expertise in one field at the expense of neglecting others is an example. This, however, does not undermine the general claim that some epistemic loss is incurred. The analogy with cases of benign manipulation is not meant to suggest that the use of a calculator implies some form of self-deception or manipulation. Instead, it only highlights an epistemic harm relevant to both cases, which is related to the fact that the epistemic outcomes are not fully creditable to the agent and in this sense do not constitute an unambiguous epistemic achievement.

The second point is more complex. It indicates a plausible link between a person's inclination to conceive her epistemic aims primarily in terms of desirable end-results and the risk of becoming less than fully creditable epistemic agent. The risk need not involve any decline in epistemic proficiency, such as reduced literacy and numeracy associated with extensive use of automatic spell-checkers and calculators, though it is consistent with such a decline. The relevant kind of harm stems from interpreting epistemic intentions as goals rather than plans, as this may alter the nature of the final achievement, independently of whether the actual epistemic route is creditable or not. Both kinds of action may lead to nearly identical outcomes, yet, the credit due to the agent varies, since each kind of action exhibits a different type of agential involvement.

The medical interventions considered as cognitive enhancements would affect epistemic achievement in relevantly similar ways. To the extent that they effectively modify a person's epistemic performance, they diminish the credit that is due to her as an agent. The fact that such cognitive enhancements are internal rather than external like calculators is beside the point. Their efficacy would equally lead to at least partial loss of epistemic credit. It may be objected that when a person takes socalled smart drugs, pharmacological products that allow her to continue working at peak capacity for longer hours, the end results should still be credited to her, since no external agency has been involved. However, the lack of intervention from outside is only a necessary condition for crediting an agent with an action. The previous example of a clumsy killer indicates that an action may be attributable to an agent and possibly engage her full responsibility without at the same time being creditable to her.

So called smart drugs and other kinds of cognitive enhancement are to be distinguished from epistemically enabling conditions, which provide prospective knowers with opportunities to both expand their competence and acquire proper credit. In order to satisfy them, the Black and Jones scenarios have to be significantly adjusted so that Black's presence encourages Jones to take on bolder epistemic tasks. Here, Black's role is to double-check Jones's results and to alert her when she is incorrect. Thus, Jones gets things right on her own, under Black's expert supervision. Black's interventions neither detract from Jones's epistemic credit, nor jeopardize her prospects of becoming a self-standing epistemic agent. The situation is relevantly similar to a successful interaction between a teacher and a pupil. If Black and Jones were one and the same person, the analogy would require that she, 
for instance, engages in a self-taught course, or improves her literacy by consulting various dictionaries and reading more widely.

As indicated by possible calculator uses, the same device may bring epistemic discredit with respect to certain tasks and, yet, serve as an enabling condition with respect to others. Relativity to specific projects does not undermine the significance of the underlying distinction, but effectively highlights its suitability for the appraisal of particular epistemic performances. This point equally applies to delegating epistemic responsibility to others. The delegating agents may deserve epistemic credit for placing their trust intelligently, however, the tasks that they have handed over will not be to their epistemic credit. With respect to cognitive enhancements, such as so-called smart drugs, this implies the possibility for partial epistemic credit reflecting the scope of actual agential involvement. Consequently, whenever the causal efficacy of purported enhancements turns out to be negligible, the epistemic agent should receive full credit for the specific achievement. Yet, even in such instances the use of cognitive enhancements potentially undermines the person as a fully creditable epistemic agent, since it weakens her commitment to epistemic pursuits as a distinctive kind of achievement.

\section{4}

The preceding Black and Jones thought-experiments illustrate four separate categories of actions, corresponding to increasingly stringent conditions of agential involvement: caused by the agent, attributable to her, responsible, and creditable actions. The first category is the most inclusive. It comprises both the sets of the remaining three and a further subset, excluded by them. The further subset is related to actions that are merely caused by an agent. Her involvement is purely instrumental, as in the scenarios in which Jones is made to perform, unbeknown to her, a particular action. It is fully attributable to Black, but involuntary, from Jones's perspective. Here, Jones is an agent only in the qualified sense of a causative substance, in which we speak of a chemical agent. The question of agential responsibility is not applicable to her.

The second category, actions attributed to an agent qua agent, brings this question in. Yet, it is still too inclusive and allows for instances, in which the agent's putative responsibility is, finally, not engaged. The clumsy killer is an example. Although he brings about the death of his intended victim, this occurs in an unforeseeable way. Being the effect of an intentional action of his, the victim's end is attributable to him. It belongs to what Donald Davidson called the "completion of his action." 12 Nevertheless, it does not engage the killer's responsibility as it would have, were he a better shot and actually hit his target. With respect to the caused fatality, the clumsy killer's involvement is relevantly similar to that of someone who trains for a shooting competition in a remote area and whose shots cause a herd of wild pigs to stampede, trampling an unexpected walker to death. A pertinent Black and Jones scenario would be as follows. Jones goes ahead with the assassination and

${ }^{12}$ Donald Davidson, op. cit., p. 71. 
the intended victim is killed. Yet, he would have missed his target, if Black did not secretly intervene.

The third category reflects a further condition, that of feasible agential control, which, however, should not be direct, nor lasting from beginning to end. This requirement both sets apart responsible from merely attributable actions and avoids the unnecessary assumption of a concurrent alternative, criticized by Frankfurt. ${ }^{13}$ It includes the foreseeable, though not foreseen effects of our intentional actions, but rules out the improbable developments, to which they might, in fact, give rise. The foreseeable effects do not presuppose the agent's ability to prevent them from happening, once the related intention has been acted upon. In the Nicomachean Ethics, Aristotle makes a similar point about responsibility for character traits: once a stable disposition vis-à-vis a particular object has been acquired, going against it may no longer be within the agent's remit. ${ }^{14}$ For instance, if stinginess has become a person's defining attitude toward money, it may be nearly impossible to display generosity, even on the rare occasions when she would like to do so. Yet, this does not exonerate mean individuals as long as their fault can be traced to previous choices. Although possibly unintended, stinginess is the natural ending of a series of intentional steps. It is, therefore, of the agent's doing and implies full responsibility, as opposed to mere attributability.

This analysis can be usefully extended to actions. It provides a plausible justification for cases, in which culpability is deemed to increase by virtue of relinquishing agential control for the culpable action. Causing an accident when driving drunk is an example. Not only is the offender held responsible for the accident that, in all likelihood, she was unable to prevent; putting herself out of control further aggravates her charge. The current practice of excluding addiction from the range of mitigating circumstances runs in a similar vein: a general duty to maintain self-control is implied; hence, being out of control provides ground for accusation rather than exculpation. ${ }^{15}$

A Black and Jones analogy would require that Jones enters a no exit clause agreement with Black, according to which Black will make him carry out the assassination even if he changes his mind and no longer wants to go along with this murderous plan. As anticipated by Jones, he does have a last minute change of heart. Black, however, fulfills his part of the deal and the assassination takes place. Jones's responsibility is engaged all the same, if not made even greater by his sinister pact to make sure that the murder gets done.

In some ways, the preceding scenario resembles the instances of self-binding, studied by Jon Elster. ${ }^{16}$ These comprise different strategies that less than fully rational agents may employ in order to avoid catastrophe, like Ulysses, who could

\footnotetext{
${ }^{13}$ See Harry G. Frankfurt, op. cit.

${ }^{14}$ Aristotle, Nicomachean Ethics, trans. W.D. Ross, The Complete Works of Aristotle, ed. Jonathan Barnes (Princeton, N.J.: Princeton University Press, 1984), 1114a4-22.

${ }^{15}$ See Gary Watson, "Excusing Addiction," Law and Philosophy, Vol. 18, (1999), pp. 597-598.

${ }^{16}$ See Jon Elster, Ulysses and the Sirens: Studies in Rationality and Irrationality (Cambridge, England: Cambridge University Press; Paris: Editions de la Maison des sciences de l'homme, 1984) and Ulysses Unbound: Studies in Rationality, Precommitment, and Constraints (Cambridge, England: Cambridge University Press, 2000).
} 
not succumb to the Syrens' temptation because his faithful companions, following his demand, kept him tied to the ship's mast. This classical story illustrates well the two defining features of self-binding. Firstly, it involves correct self-assessment as being unable to deal with a particular weakness, such as insatiable curiosity in the case of Ulysses. Secondly, the identified weakness is tackled by delegating control to reliable others. Thus, self-binding satisfies the conditions of feasible agential control, as outlined earlier. In this respect, it is alike the preceding Black and Jones variation. Furthermore, it suggests that feasible agential control may sometimes suffice for attributing not only negative responsibility, but also credit for actions. For instances of self-binding clearly exhibit a kind of achievement. It enables agents to counterbalance their own limitations and circumvent anticipated disaster.

This point supports the conclusions that were reached earlier. There, achieving an epistemic goal either via Black's intervention or via some enhancing technique was suggested not conducive to full epistemic credit. This can now be explained as a kind of self-binding, by which an agent may get round some cognitive deficiency and secure an epistemically valuable result. Yet, self-binding leads to no more than a derivative praise since the agent is, effectively, credited for avoiding foreseeable blame. Her achievement is conditional on a persistent flaw. She resists temptation, but does not display self-restraint. The warranted credit does not extend to the quality, which she clearly lacks. A further limitation on praise for self-binding comes from the fact that it may reinforce the particular weakness, it helps the agent to cope with. By alleviating its detrimental consequences, self-binding makes it less urgent to address the weakness itself. Self-binding is, therefore, a fundamentally ambivalent kind of achievement. It is consistent with both types of self-harm, identified earlier. This marks a crucial difference with enabling conditions, which warrant full agential credit.

\section{5}

Conditions warranting full agential credit are distinguishing features of the fourth category of actions. It presupposes a more demanding agential involvement than just feasible control. This leaves out many aspects of broader responsibility, such as backfiring activities, negligent actions, and failures to act in a particular way. In contrast, in order to be creditable, an action has to both realize certain value and express the agent's commitment to it. Obvious examples are morally virtuous actions, which Aristotle discusses in the Nicomachean Ethics. ${ }^{17}$ Being expressive of a relevant quality, or virtue of the agent partly defines such actions. For instance, remaining calm in the face of danger should not to be praised as an act of courage, unless it is done out of courage. Conversely, outwardly identical behavior, due to taking a pill that suppresses the emotional response to the situation, should not be considered as courageous, since it does not display a worthy disposition vis-à-vis danger. The two courses of action may have the same effects, yet, they fundamentally differ in both nature and value. Only the action done out of courage

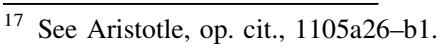


instantiates the value of courage and is, therefore, creditable to the agent as an act of courage. The action due to taking a pill cannot be to the agent's credit in the same respect. It displays her indifference to the value of courage. This confines it to the status of a secondary action, or poiesis, the value of which is fully reducible to that of its consequences. ${ }^{18}$ Thus, agential lack of commitment to a pertinent value, which, on such an occasion, is courage, both devalues and downgrades her action. As a result, it cannot qualify as an action proper, or praxis, which is also worthy independently from its desirable effects. Secondary actions lack this immediate and indissoluble connection to value. They are creditable only conditionally, in so far as they bring about consequences of some worth.

This suggests that full agential credit depends, to a considerable degree, on the agent's competence as a valuer. We are unable to creditably instantiate values that fall outside our evaluative spectrum and should not be credited for inadvertently promoting them. This, however, neither makes relevant actions inattributable to an agent, nor precludes them from being creditable to her in another sense: as a selfbinding, secondary action, or even, an instantiation of an alternative, accessible to the agent, value.

In the Eudemian Ethics Aristotle provides a helpful example, which he calls the Spartan disposition. ${ }^{19}$ This is a special case of moral snobbery, where character virtues are appreciated exclusively for their overall beneficial effects. Their perceived value is, therefore, reduced to that of a competitive advantage in the pursuit of social status and wealth. From the Spartan perspective, the value of courage resides in the good prospects of meeting our goals in spite of adversity. Similarly, the worth of temperance is confined to its anticipated pay-off, such as staying beyond reproach. Importantly, the resulting behavior is not without merit. It is a decent pursuit of social advancement, which does not employ violent, corrupt, or devious means. Yet, it is fundamentally deficient. It leaves out the independent, moral worth of character virtues and, therefore, fails to implement it. In this respect, the so-called Spartan motivation importantly downgrades the prospective achievement and credit that the agent could get. It excludes the distinctive accomplishment and reward, which come through the exercise of a virtue. Conversely, the appreciation and practice of ethical virtues as valuable in themselves is compatible with a commitment to further pursuits, such as prosperity. It allows for a broader range of creditable options than the Spartan disposition.

The appeal of cognitive enhancement implies an analogous attitude toward epistemic achievement. Intellectual virtues in the broad sense of outstanding intellectual qualities are appreciated primarily for the anticipated social advantage, which, though steadily associated with their exercise, remains epistemically peripheral. As a result, the perceived value of intellectual virtues is essentially confined to that of a competitive edge in an underlying rivalry for excludable goods, such as prestige and fortune. This is consistent with the focus on fairness, which

\footnotetext{
18 See ibid. 1140a1-19.

19 See Aristotle, Eudemian Ethics, trans. J. Solomon, The Complete Works of Aristotle, ed. Jonathan Barnes (Princeton, N.J.: Princeton University Press, 1984), 1248b-49a18.
} 
characterizes many recent discussions on cognitive enhancement. ${ }^{20}$ From this perspective, cognitive enhancements may provide, as long as they are sufficiently reliable, just the same desirable outcomes. The outcomes, however, are mere byproducts of intellectual achievement. This point applies, mutatis mutandis, even to technical expertise and practical know-how. Their exercise is also worthwhile in its own right, independently of their sought-after results. In so far as this exercise realizes a valuable disposition, it qualifies as an action proper, not only as a secondary action.

Following this line of thought it becomes apparent that the notion of cognitive enhancement implies a Spartan-like attitude to cognition. Thus, epistemic harm is already instigated by the failure to appreciate intellectual achievement in its own right. In this respect, the very framing of the cognitive enhancement debate in distributive terms such as fair access may be epistemically undermining. ${ }^{21}$

Open Access This article is distributed under the terms of the Creative Commons Attribution Noncommercial License which permits any noncommercial use, distribution, and reproduction in any medium, provided the original author(s) and source are credited.

\footnotetext{
${ }^{20}$ See John Harris, op. cit. See also Maartje Schermer, "On the Argument that Enhancement is 'Cheating'," Journal of Medical Ethics, Vol. 34, No. 2, (2008).

21 I would like to thank Jane Heal, Ulrich Muller, Hallvard Lillehammer, the anonymous referees and Thomas Magnell, Editor-in-Chief of the Journal of Value Inquiry for their constructive comments. I would also like to acknowledge the support received from the Wellcome Trust, U.K. (Ref: 081498/Z/06/Z).
} 